\title{
Absolute identification of notes and intervals by musicians
}

\author{
JANE A. SIEGEL and WILLIAM SIEGEL \\ University of Western Ontario, London, Ontario, Canada
}

\begin{abstract}
Speech sounds are judged reliably and absolutely, while the judgment of nonspeech stimuli, such as tones, is thought to be unreliable and dependent on contextual cues. Here we demonstrated that the judgment of tonal stimuli may also be reliable and absolute, provided that the subjects are trained musicians. In Experiment 1, musicians with relative pitch identified 21 tonal intervals ranging from unison to major third, and the resulting identification functions were similar to those that have been previously obtained for speech. In Experiment 3 , the judgment of intervals by musicians was shown to be free of context effects, since the best subjects gave virtually identical judgments to the same intervals in two stimulus contexts. Similar results were obtained in Experiments 2 and 4 for the judgment of single tones by possessors of absolute pitch. Performance with both notes and intervals by nonmusicians, however, was unreliable and greatly influenced by context. These findings suggest that musicians acquire categories for pitch that are functionally similar to phonemic categories for speech.
\end{abstract}

Our ability to make absolute judgments of stimuli varying along a single sensory dimension is thought to be severely limited - the so-called "magical number seven phenomenon"' (Miller, 1956). Most of us can identify only about four or five tonal stimuli varying in pitch or loudness without confusion (e.g., Pollack, 1953), and even then our judgments are not truly "absolute." Rather, they are based upon contextual cues such as the preceding stimulus or the end-points of the stimulus range (e.g., Durlach \& Braida, 1969; W. Siegel, 1972; Ward \& Lockhead, 1970).

A major exception to this rule comes in the area of speech perception, where there are a variety of acoustic dimensions that relate the different phonemes of a language system. For example, the English consonants $/ b /$ and $/ p /$ are related along the continuum of voice onset time, as are the other voiced and voiceless stops, $/ \mathrm{g} /-/ \mathrm{k} /$ and $/ \mathrm{d} /-/ \mathrm{t} /$ (Lisker \& Abramson, 1964). When listeners are presented with synthetic speech sounds varying in voice onset time, they are able to identify the stimuli as examples of the appropriate phoneme class, and there is good agreement among speakers of a language about the transition from a voiced to a voiceless stop. Labeling distributions for speech sounds, particularly the stop consonants, are regular

These experiments were reported at the 90th Meeting of the Acoustical Society of America, San Francisco, November 1975. We thank the National Research Council of Canada for its support (Grants A7895 and A8581). Vickey Woods and Robert Sopo were most helpful in collecting the data. Requests for reprints should be sent to Jane A. Siegel, Department of Psychology, University of Western Ontario, London, Ontario, Canada. and symmetrical, with little overlap between adjacent categories, and with steep category boundaries (see Studdert-Kennedy, Liberman, Harris, \& Cooper, 1970). Moreover, unlike tonal stimuli, consonants are apparently judged on a truly absolute basis, since the phonemic category boundaries are relatively invariant when the stimulus context is shifted (Sawusch \& Pisoni, 1974; Sawusch, Pisoni, \& Cutting, 1974).

What is the basis for the gross difference in the ease of identification of speech and nonspeech continua? There are data which show that speech categories are present at a very early age (Eimas, 1975; Eimas, Siqueland, Jusczyk, \& Vigorito, 1971), and it has been suggested that they are mediated by innate neural feature detectors. On the other hand, cross-language research has indicated that speech categories are also dependent on the linguistic experience of the listener (Abramson \& Lisker, 1970; Miyawaki, Strange, Verbrugge, Liberman, Jenkins, \& Fujimura, 1975). This suggests that learning also plays a role, and it is possible that reliable, context-free identification might be developed even for nonspeech sensory continua, given sufficient opportunity for learning. For, while we spend much of our early years learning to encode and decode language, few of us ever have had similar experience in the identification of pitch or loudness.

We have argued elsewhere (Siegel \& Siegel, 1972; W. Siegel, 1972) that the span of absolute judgments for nonspeech sensory continua is not a basic perceptual limitation, but rather results from poor memory for the unfamiliar stimuli typically used in psychophysical experiments. There is evidence that the identification of sensory stimuli can be substantially improved by practice, especially when the 
training procedures encourage active encoding, rather than rote learning (Brady, 1970; Cuddy, 1968). A good example of the effects of such training outside of the laboratory comes from music. Most musicians have acquired relative pitch, the ability to identify tonal intervals on an absolute basis. A much smaller number of musicians possess absolute pitch, the ability to identify single tone frequencies (Ward, 1963a, b).

Both relative and absolute pitch are interesting exceptions to the "magical number seven problem." Moreover, their existence suggests that the effects of training on the identification of stimuli varying along a single sensory dimension have been greatly underestimated. It was our purpose here to examine the degree to which trained musicians with absolute or relative pitch can make judgments of notes or intervals on an absolute, context-free basis. We hypothesized that the results should be similar to those found in experiments investigating the absolute identification of speech sounds.

\section{EXPERIMENT 1: IDENTIFICATION OF TONAL INTERVALS BY MUSICIANS WITH RELATIVE PITCH}

Relative pitch may be defined as the ability to identify, on an absolute basis, the standard tonal intervals provided by a musical scale. In Western music, the well-tempered scale divides each octave into 12 logarithmically equal steps, so that adjacent notes are related to one another by a semitone, i.e., a frequency ratio of 1.059:1. Each of the standard intervals is assigned a unique name, such as unison, perfect fifth, or tritone, and "ear training" consists at least in part of learning to attach these labels to the appropriate frequency ratios. This is a difficult task, and musicians adopt a variety of tricks to make the problem more tractable. One standard technique is to associate an interval with a familiar melody. For example, one can get the interval of a major sixth by thinking of the first two notes of "My Bonnie Lies. Over the Ocean." Another technique, the Tonic Solfa method, involves the association of distinctive syllables, gestures, and connotations to intervals. With the Tonic Solfa method, students are taught that the major third, $m i$, is referred to as the "STEADY or calm tone, fingers extended and horizontal and undermost," that the fourth has a "desolate" or "awe-inspiring" character, and so forth (cf. Hemlholtz, 1954, pp. 279-280).

What effect does this type of training in interval recognition have on musicians' labeling performance? We attempted to answer this question here by testing the ability of subjects to assign standard musical names to computer-generated tonal intervals. It was our hypothesis that musicians would generate identification functions for intervals that resemble those found in similar experiments involving the identification of synthetic speech sounds. That is, we predicted that the musicians would produce reliable naming distributions with little overlap between adjacent categories, and sharp, welldefined category boundaries.

\section{Method}

Subjects. In this study, 32 subjects with varying degrees of relative pitch were tested. Of these, 25 were either professional musicians or students at the Universiy of Western Ontario's School of Music. The remainder were specifically selected for their lack of musical experience. None reported any hearing disabilities. All subjects received $\$ 3 / \mathrm{h}$ for their services.

Apparatus. The subjects listened to sine-wave tones produced by a Wavetek oscillator, and delivered through Clark 100 headphones. A small laboratory computer (DEC PDP-12) was used to control the output of the oscillator, to present the stimulus sequence, to collect subjects' responses, and for data analysis. We have found that, with this system, the control of tone frequency is accurate to within $.1 \mathrm{~Hz}$. The subjects entered their responses by pressing one of an appropriately labeled horizontal array of pushbuttons.

Procedure. The subjects listened to a set of 21 different tonal intervals ranging over five semitone categories defined by the Western tempered scale, from unison (a frequency ratio of 1:1) to a major third $(1.26: 1)$ in 20-cent steps. The first note of each interval was an accurate $C(261.6 \mathrm{~Hz})$. Subjects were told to label the intervals by assigning them to one of the following five categories: unison, minor second, major second, minor third, and major third. Each interval consisted of two .25 -sec sinusoids separated by a 1 -sec silent period. The task was self-paced and no feedback was provided. An experimental session consisted of 10 blocks of trials, and within each block, the 21 different intervals were presented once each in random order. Each subject was tested on two sessions, and so that we could check the reliability of interval naming, we allowed at least 1 month to elapse between the first and second sessions.

\section{Results and Discussion}

Figure 1 shows naming distributions generated by the four musicians whose performance we judged to be most consistent. Each panel shows the percentage of times that an observer used each of the five response categories to identify each stimulus interval. This mode of analysis is similar to that employed by a number of writers to examine identification of synthetic speech signals (Studdert-Kennedy et al., 1970). Our results are characterized by (a) consistent use of all five response categories; (b) regular, symmetrical naming distributions; (c) sharp, welldefined category boundaries; and (d) good correspondence between the results of two test sessions separated by over 1 month.

There appear to be some idiosyncratic differences between subjects in their categorization of the five musical intervals covered by the stimulus range. For example, K.A. produced a relatively wide minor second category and a somewhat narrower major second distribution while for M.W., the opposite was true. These individual differences were consistent over the two test sessions.

The results of four nonmusical subjects are plotted 

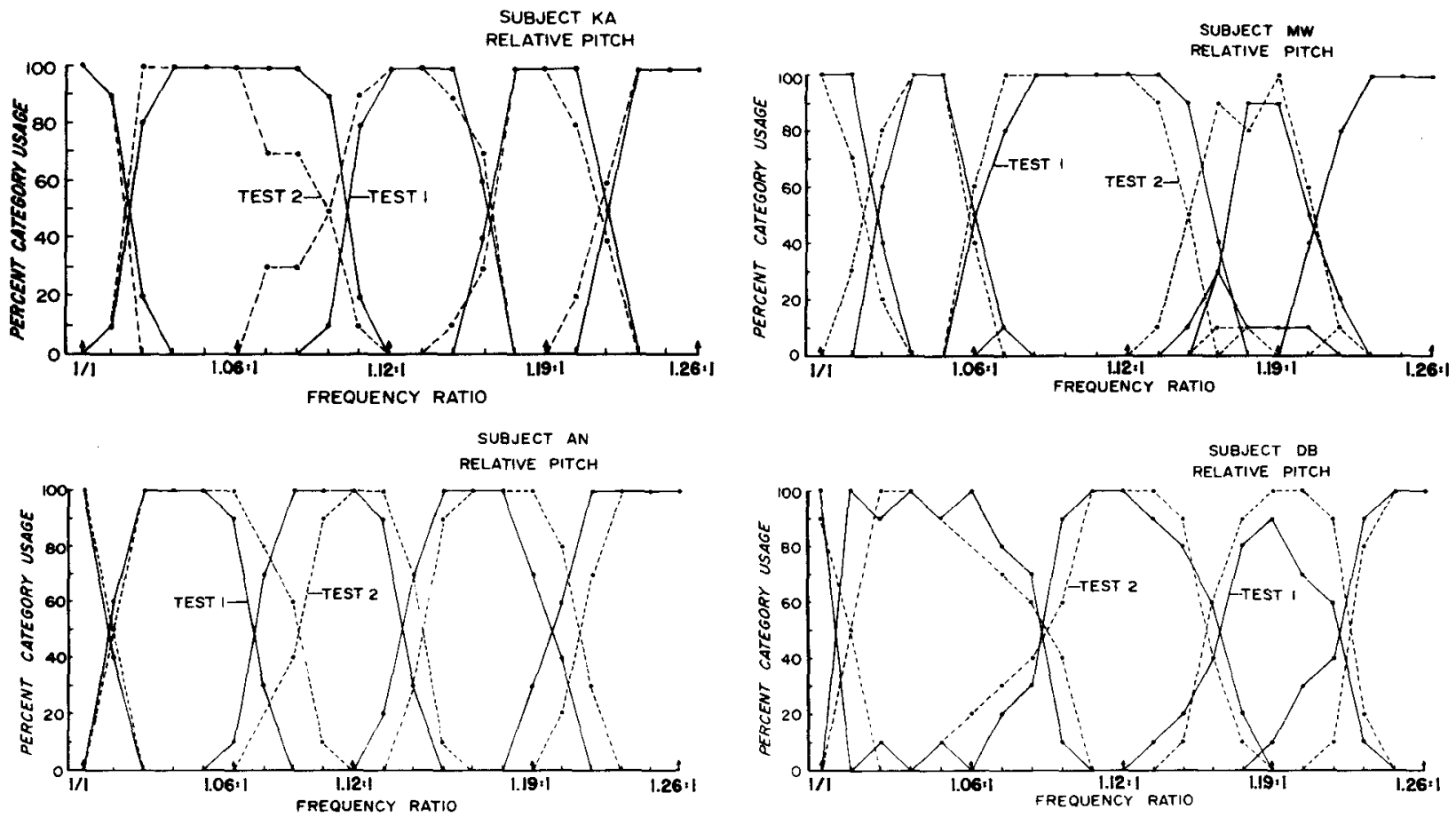

Figure 1. Identification of tonal intervals by four musicians with relative pitch.

in Figure 2, and they indicate that identification of tonal intervals is far from a trivial task for someone lacking musical training. The control data show inconsistent response usage both within and across sessions. The only exception to this rule is in the use of the unison category, but this is not surprising, since it can be used correctly on the basis of contextual cues. That is, subjects can use the unison response when they detect a null match between the two notes of the interval (cf. Weintraub, 1971).

Our best musicians produced data that compare favorably with similar identification functions published in the speech literature (e.g., Liberman, 1970). These results seem particularly impressive, since comparable studies of speech continua have used a maximum of three response categories, while
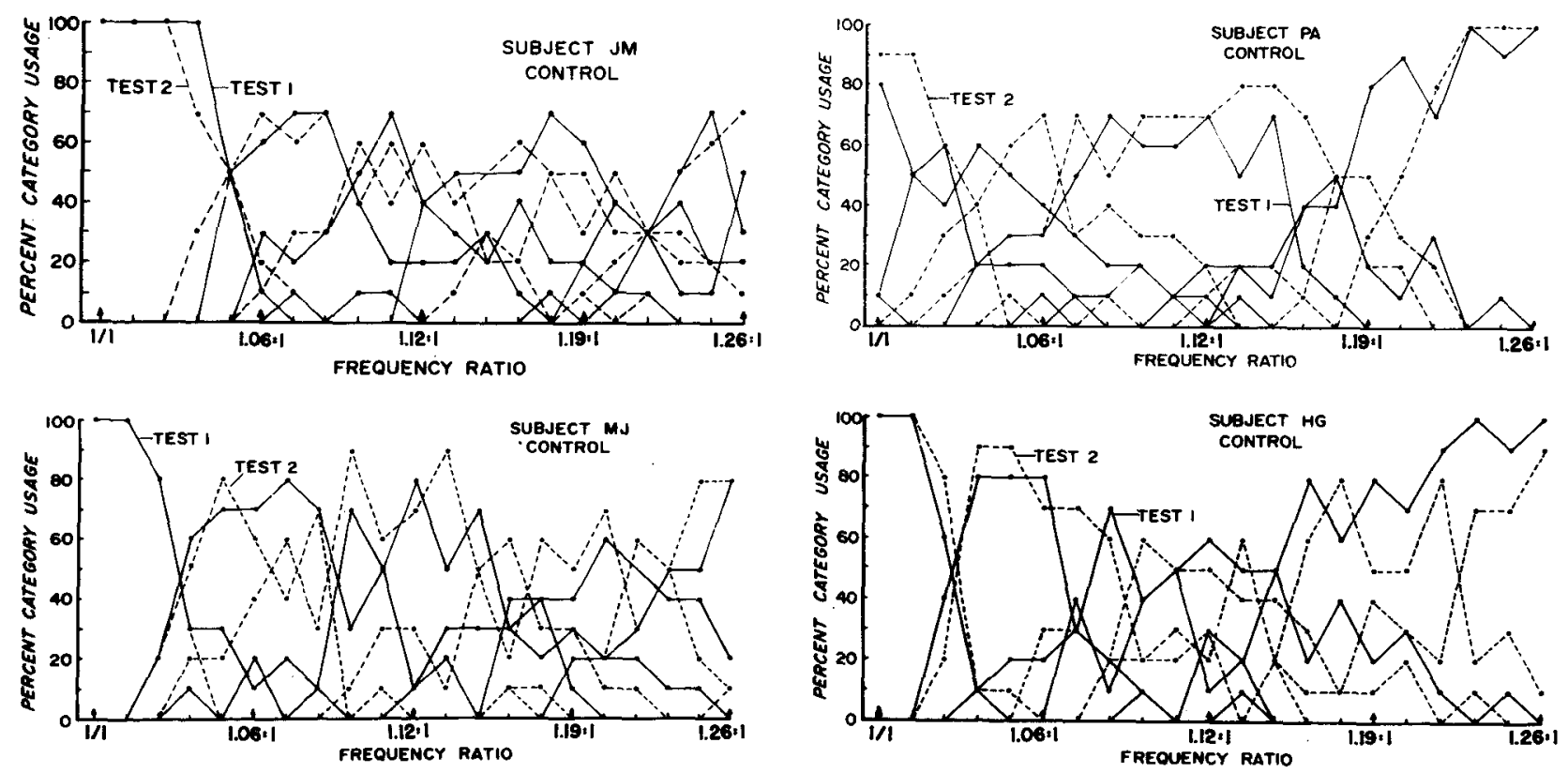

Figure 2. Identification of tonal intervals by four nonmusical control subjects. 
the present experiment used five. We conclude that, as a result of extensive training, musicians have established a set of absolute mnemonic anchors which represent the standard semitone intervals defined by their subculture. Lacking such interval anchors, nonmusicians must adopt the contextcoding strategy that results in the low level of performance typically associated with absolute identification of nonspeech sensory continua (e.g., Durlach \& Braida, 1969).

\section{EXPERIMENT 2:}

\section{IDENTIFICATION OF TONE FREQUENCY BY MUSICIANS WITH ABSOLUTE PITCH}

Some time ago, Petran (1932) defined absolute pitch as "...the remarkable ability possessed by certain few musicians (and an occasional idiot savant) to give quickly and correctly, without reference to any standard tone, the names of tones they hear, and also the ability which still fewer musicians have to sing or whistle any tone which may be called for by name" (p. 1). There are reports in the literature of possessors of absolute pitch who are able to identify any of the 88 piano notes with only an occasional error (cf. Ward's 1963a, b review). We have tested musicians who are capable of this level of pitch-naming ability even when the tones are sinusoids rather than piano notes, and so timbre cues do not appear to be essential for absolute pitch.

Despite the fact that absolute pitch has been of interest to psychology since the time of Stumpf (1883), little agreement has been reached on a theory of absolute pitch, or even on how the phenomenon is to be defined. Most of the controversy has focused on the nature-nurture issue, with the combatants generally falling into one of two camps. On the one hand, there are the investigators who claim to be possessors themselves, and who have done little to discourage the belief that absolute pitch is a unique, innate gift that sets them apart from other musicians (Bachem, 1937; Révész, 1913). Then there are the psychologists who are nonpossessors, most of whom treat absolute pitch as an extreme case of pitch-naming ability that can be acquired through practice (e.g., Brady, 1970; Meyer, 1899; Mull, 1925; Neu, 1947). This view is supported by the finding that the distribution of pitch-naming ability appears to be continuous, rather than bimodal (Oakes, 1955; Riker, 1946). Thus the distinction between "possessors" and "nonpossessors" of absolute pitch is somewhat arbitrary.

In this experiment, we examined the identification functions of musicians at the upper end of the pitch-naming continuum, and contrasted their performance with persons low in pitch-naming ability. We expected the identification functions of the best absolute pitch subjects to resemble those that we found in Experiment 1 for naming of musical intervals, and also those reported in studies examining the identification of speech sounds.

\section{Method}

Subjects. Seven musicians claiming absolute pitch and four nonmusicians were tested in this experiment. The subjects were paid $\$ 3 / \mathrm{h}$ for participating, and none reported any hearing disability.

Apparatus and Procedure. The details of the experiment were identical to those of Experiment 1, except that the stimulus on each trial was a single tone, rather than an interval. The stimuli covered a range of $\mathrm{C}(262 \mathrm{~Hz})$ to $\mathrm{E}(330 \mathrm{~Hz})$ in 20 -cent steps. Subjects labeled the stimulus set by pressing the appropriate pushbuttons, in this case marked C, C\#, D, D\#, and E. Again, there were two sessions separated by at least 1 month.

\section{Results and Discussion}

The identification functions of the three most consistent absolute pitch subjects and three controls are shown in Figures 3 and 4. The data of the absolute pitch subjects are accurate and reliable, although not quite as clean as the results for the identification of tonal intervals obtained in Experiment 1. Perhaps this reflects the relative importance of absolute and relative pitch in our musical culture. The performance of our control subjects was extremely inconsistent, indicating that the regular, symmetric, and reliable naming distributions produced by the absolute pitch group are not based upon contextual cues present in the experiment. Rather, the musicians appear to be responding on an absolute basis to tone frequency, in a manner more usually thought to be characteristic of speech.

\section{EXPERIMENT 3:}

\section{CONTEXT-FREE JUDGMENT OF INTERVALS BY MUSICIANS WITH RELATIVE PITCH}

In Experiments 1 and 2, we demonstrated the reliable use of note and interval categories by possessors of absolute and relative pitch. Here we focused more explicitly on the degree to which musicians' judgments of pitch are dependent upon contextual cues. This was accomplished by requiring subjects with varying degrees of relative pitch to judge a set of tonal intervals in two different stimulus contexts. First they were presented with 21 intervals ranging from a minor second to a perfect fourth for six blocks of trials. Then they were shifted without warning to a new stimulus series, which contained the 11 largest intervals from the preshift set plus 10 larger ones. The typical result of such a shift is judgmental contrast (cf. Helson, 1964), a tendency to judge the common stimuli as smaller in the postshift context of larger intervals. Contrast effects are maximal when the stimuli have no overlearned mnemonic anchors, and they can be accounted for by a bias to distribute an arbitrary set of responses 

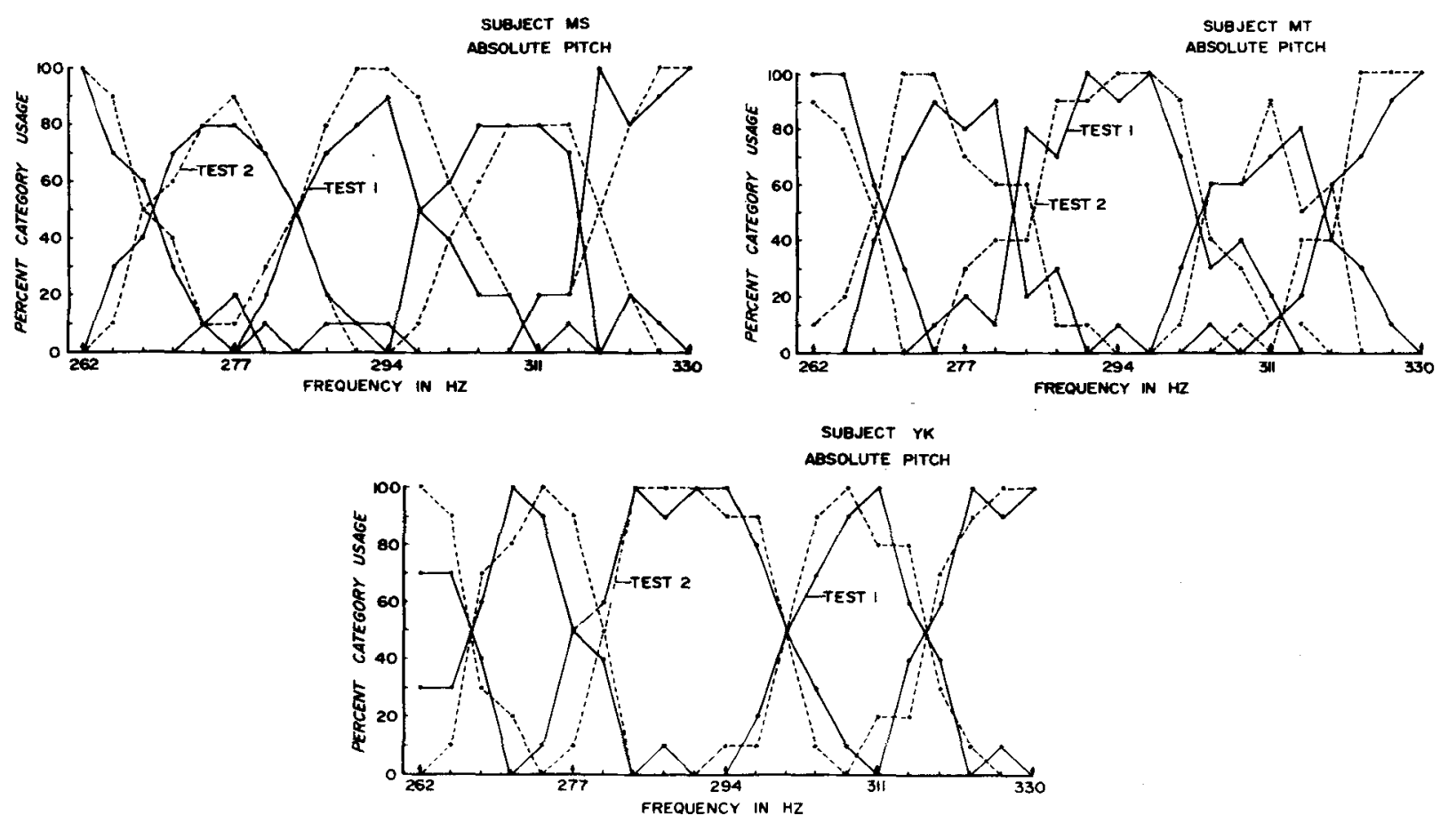

Figure 3. Identification of tone frequency by three musicians with absolute pitch.

over whatever stimulus range is employed in the experiment (DiLollo \& Kirkham, 1969; Ross \& DiLollo, 1971).

While there are substantial context effects in the judgment of pitch and loudness, there are no such effects for synthetic speech sounds (Sawusch \& Pisoni, 1974; Sawusch et al., 1974). This may be because the phonetic categories for speech are built in (Eimas et al., 1971), or it may reflect the differential familiarity of subjects with speech and nonspeech continua. The purpose of this experiment was to examine whether the judgments of tonal intervals by highly trained musicians are insensitive to variations in the stimulus context, as is the case for speech.
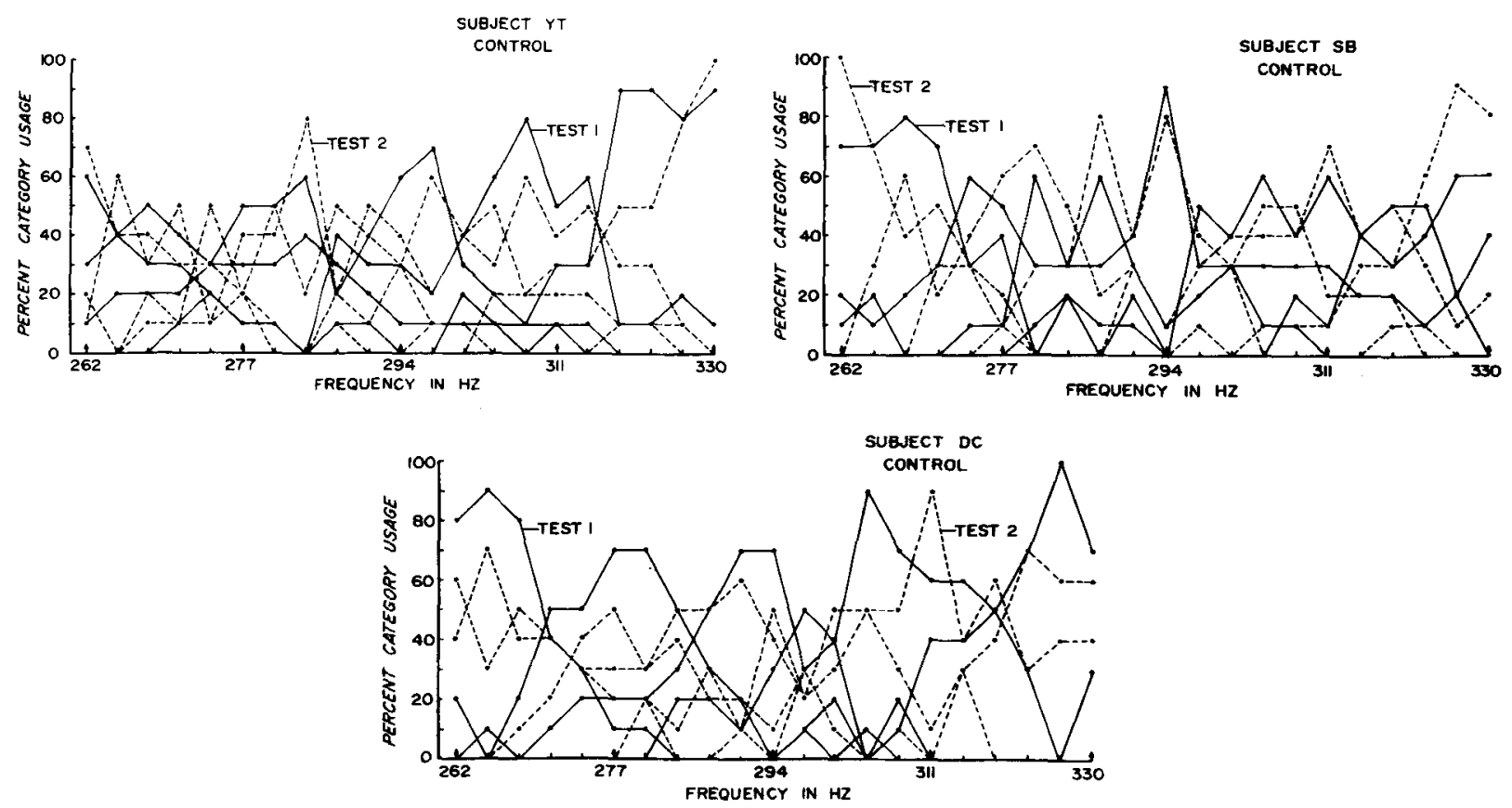

Figure 4. Identification of tone frequency by three nonmusical control subjects. 


\section{Method}

Subjects. The subjects included 14 observers with varying degrees of relative pitch. Some, but not all, of these also participated in Experiment 1. Seven were either students enrolled at the university's School of Music or were performing actively in local groups. The remaining seven were undergraduate students with little or no formal musical training. All were paid $\$ 3 / \mathrm{h}$ for participating.

Pretest. Relative pitch ability was assessed in a pretest, in which subjects identified seven musically accurate intervals defined by the Western tempered scale. Each interval was presented twice in random order, and subjects attempted to identify the stimulus by pressing the correct pushbutton from a set labeled with the appropriate interval names. No feedback was given. Performance ranged from $28 \%$ to $100 \%$ correct.

Procedure. The experimental paradigm was the method of magnitude estimation. In a pilot experiment, we used an identification task similar to that of Experiment 1, and found that the control subjects used all the available responses in judging the preshift stimulus series, leaving them with no additional responses for judging the new stimuli in the postshift series. As Parducci (1965) has pointed out, this situation is likely to occur in any paradigm which requires the subjects to use a restricted response range, leading to an artifactual contrast effect. The magnitude estimation task places no restrictions on the range of numbers used by subjects. The apparatus was identical to that of Experiments 1 and 2, except that subjects entered their responses on the keyboard of a video terminal. They were instructed to judge the distance between the two notes comprising a tonal interval, making their judgments as fine-grained as possible. The experiment began with three presentations of the standard interval, to which subjects were asked to assign any number over 100 . They were then required to make their responses to intervals presented in the body of the experiment proportional to their judgment of the standard. For example, if the interval seemed twice as large as the standard, they were to assign it a number twice as large. Length was used as an analogy.

The preshift series consisted of 21 intervals ranging in 20-cent steps from a minor second to a perfect fourth. Subjects received six blocks of trials, each containing the 21 stimulus intervals in random order. There was a brief rest period between blocks. The details of stimulus presentation were identical to those of Experiment 1.

Following the sixth block of trials, the subjects were shifted without warning to a new stimulus set containing the 11 largest intervals from the preshift series, plus 10 larger intervals. The postshift series ranged from a minor third to a perfect fifth in 20 -cent steps. This new set of stimuli was judged for an additional six blocks of trials.

\section{Results and Discussion}

The typical result of a shift in the stimulus context is to produce judgmental contrast. Since, in this experiment, the postshift context was of larger magnitude than the preshift one, a contrast effect would result in lower postshift judgments for the 11 stimuli that were common to the pre- and postshift series. A preliminary inspection of the data revealed that our subjects had used widely differing response ranges, making the importance of any individual's postshift decrement in judgment difficult to evaluate in absolute terms. Each subject's judgments were therefore converted to standard scores, based on the mean and standard deviation of his responses to the 11 common tones for the six preshift blocks of trials. All further data analyses were carried out using these standard scores. By definition, each subject's standard score for the six preshift blocks is zero. The postshift scores, however, would be negative for those subjects who exhibited a judgmental contrast effect.

Figure 5 shows results for the relative pitch experiment. In preparing Figure 5, we selected the four subjects who had scored $100 \%$ correct on the interval identification pretest to form the relative pitch group, and compared their performance with that of a control group, which consisted of the four subjects who had the worst performance on that test. For both groups, the mean postshift judgment, averaged over subjects and the 11 common stimuli, is plotted for each postshift block of trials. As was mentioned earlier, the average standard score for the preshift blocks is zero by definition, and this is indicated in the figure.

For the relative pitch group, the shift in context had little effect, while for the control group there was a substantial contrast effect, one which seemed to build up over blocks of trials. One would expect such a buildup to occur, as subjects' memory of the preshift context fades and becomes less influential in determining their responses. An analysis of variance on the postshift data revealed that the effect of Groups (relative pitch vs control) was significant, $F(1,3)=21.6, p<.025$. The effect of Trials failed to reach significance, $\mathrm{F}(5,15)=1.16, \mathrm{p}>.05$, as did the Trials by Groups interaction, $F(5,15)<1$. The latter finding indicates that the increase in contrast over trials in the control group is not reliable, but the number of subjects tested here was small.

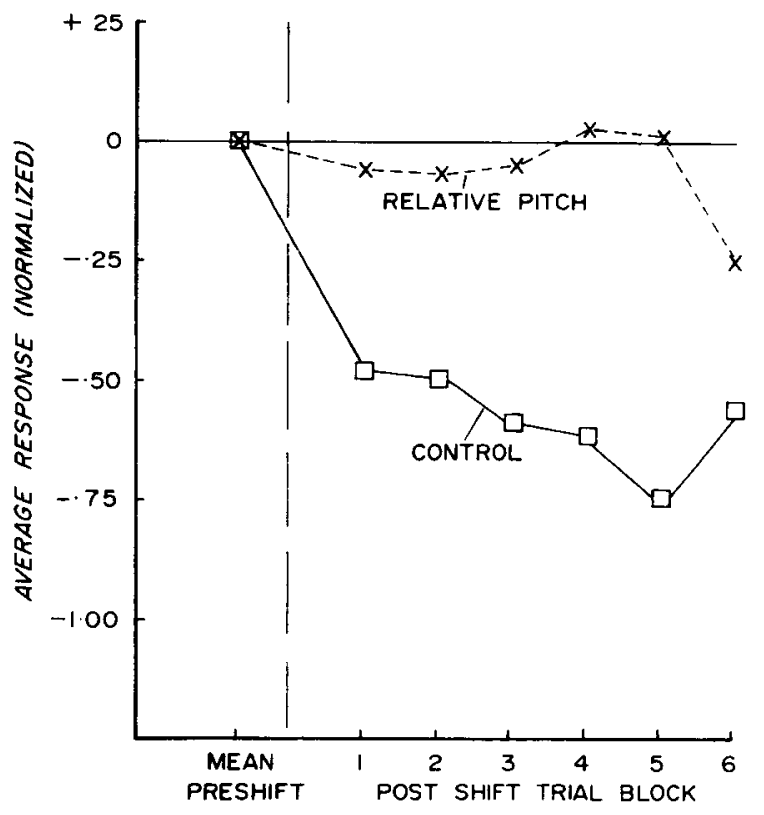

Figure 5. Mean magnitude estimates of tonal intervals by musicians and nonmusicians following a shift in the stimulus range (standard scores). 
An interesting question is whether there was any influence of the context shift for the four best relative pitch subjects. The answer appears to be no, although the number of subjects tested here was too small to allow a definitive answer. For two of the four subjects, the mean postshift standard score was slightly positive, and for two, it was slightly negative. A t test indicated that the musicians' postshift contrast was not significantly different from zero, $t(3)=$ .56. On the other hand, all four control subjects showed contrast, and the group postshift mean was significantly different from zero, $t(3)=-11.56$, $\mathrm{p}<.001$.

In Figure 5, we selected subjects simply on the basis of their interval identification ability. Table 1 presents information about the musical background of all 14 listeners, as well as measures of their performance in the interval identification and context shift tasks. We have placed the subjects into three categories. First, there were seven highly musical listeners, all of whom played several instruments, could read music, and were actively involved in the performance of music at the time of the experiment. None of these listeners scored less than $85 \%$ correct in the interval identification experiment, and on the average, they showed no evidence of judgmental contrast $(\bar{Z}=.03)$. Second, there were five decidedly nonmusical subjects. None were able to read music or to play an instrument, except for P.B., who described himself as "an intermediate beginner" on the guitar. All of the nonmusicians showed contrast in the shift task $(\bar{Z}=-.71)$, and their scores did not overlap with those of the musical group. Finally, there were two individuals, W.L. and P.A., who, while not currently music students, had some musical background. Their performance in the interval identification task over- lapped with that of the nonmusicians, but they showed less contrast in the shift experiment.

In addition, we correlated the average error of each subject in the interval identification pretest with his postshift standard score, and found a statistically significant relationship between intervalnaming ability and susceptibility to context effects, $\mathrm{r}=-.63, \mathrm{p}<.01$. All of these analyses lead us to the conclusion that active musicians with good relative pitch have acquired absolutely anchored interval categories that are minimally disrupted, if at all, by changes in the tonal context.

\section{EXPERIMENT 4: EFFECT OF CONTEXTUAL CUES ON THE MAGNITUDE ESTIMATION OF TONE FREQUENCY BY MUSICIANS WITH ABSOLUTE PITCH}

Experiment 3 demonstrated a relationship between relative pitch ability and the degree of reliance upon contextual cues for the judgment of intervals. The best relative pitch subjects showed essentially no judgmental contrast when the stimulus range was shifted in a magnitude estimation task. Experiment 4 was a replication of Experiment 3, except that the subjects were persons possessing various degrees of absolute pitch, and the stimuli were single tones, rather than intervals. We expected that the best absolute pitch subjects would make their judgments of pitch independently of the stimulus context, thus providing a further parallel between the processing of music and speech.

\section{Method}

Subjects. The subjects were 27 individuals with varying degrees

Table 1

Musical Background and Interval Identification Ability of 14 Listeners in Experiment 3

\begin{tabular}{|c|c|c|c|c|c|}
\hline Subject & $\begin{array}{l}\text { Percent Correct } \\
\text { Interval Identi- } \\
\text { fication }\end{array}$ & $\begin{array}{c}\text { Number Instru- } \\
\text { ments Played }\end{array}$ & $\begin{array}{c}\text { Hours/Week Active } \\
\text { Participation in } \\
\text { Music }\end{array}$ & Read Music? & $\begin{array}{l}\text { Postshift } \\
\text { Z-Score* }\end{array}$ \\
\hline MW & 100 & 5 & 40 & Yes & +.11 \\
\hline $\mathrm{BF}$ & 100 & 3 & 45 & Yes & +.08 \\
\hline $\mathrm{BT}$ & 100 & 3 & 4 & Yes & -.28 \\
\hline GS & 100 & 5 & 2 & Yes & -.18 \\
\hline $\mathbf{J F}$ & 93 & 4 & 25 & Yes & -.16 \\
\hline ST & 93 & 3 & 7 & Yes & +.16 \\
\hline RM & 86 & 6 & 16 & Yes & +.47 \\
\hline WL & 64 & 2 & 0 & Yes & -.12 \\
\hline PA & 36 & 2 & 10 & Yes & -.43 \\
\hline PL & 64 & 0 & 0 & No & -.50 \\
\hline PB & 57 & 1 & 3 & No & -1.24 \\
\hline $\mathrm{EB}$ & 43 & 0 & 0 & No & -.62 \\
\hline BI & 28 & 0 & 0 & No & -.64 \\
\hline PK & 28 & 0 & 0 & No & -.53 \\
\hline
\end{tabular}

*Averaged over the six postshift blocks of trials. 
of absolute pitch ability. Twelve were musicians who claimed to possess absolute pitch, 12 were musicians who did not claim absolute pitch, and 3 were nonmusicians. The subjects were paid $\$ 3 / \mathrm{h}$ for participating.

Pretest. Absolute pitch ability was assessed in a pretest, in which subjects identified 12 randomly presented notes defined by the Western scale. No feedback was given, and the procedure was similar to that used in Experiment 3. Their performance varied from $0 \%$ to $100 \%$ correct.

Procedure. The subjects were tested in a magnitude estimation experiment, in which they judged 21 different tone frequencies presented once each in random order in a block of trials. Immediately prior to the test, they listened to three presentations of a standard stimulus $(294 \mathrm{~Hz}$, an accurate D), and were asked to assign it any value over 100 . They were instructed to make ratio judgments of the perceived tone height of each stimulus relative to the standard, and length was used as an analogy. For the first six blocks of trials the stimuli ranged in 20-cent steps from $\mathrm{C}(262 \mathrm{~Hz})$ to $\mathrm{E}(330 \mathrm{~Hz})$. In Blocks $7-12$, the stimulus range was shifted without warning so that the endpoints were $D(294 \mathrm{~Hz})$ and $F \#(370 \mathrm{~Hz})$. Eleven stimuli were common to the preshift and postshift series. All other aspects of the apparatus and procedure were identical to those employed in Experiment 3.

\section{Results}

Figure 6 shows the mean response magnitude to the common stimuli plotted for the six post-shift trial blocks. Here, the "absolute pitch" group consists of six subjects who had scored $100 \%$ correct in the note identification task, while the control group consists of the six subjects who scored lowest in the note-identification pretest. As in Experiment 3, each subject's results are normalized on the basis of his preshift judgments, to correct for individual differences in the preferred response range. As a result, negative scores indicate judgmental contrast.

As in the relative pitch study, there is a substantial contrast effect for the control subjects which appears to become more pronounced over the six postshift blocks. This trend is identical to that shown in Experiment 3 for interval judgments by nonmusicians, but as in that study, the effect is not reliable. The absolute pitch group, on the other hand, shows little effect of the context shift. An analysis of variance revealed that the control group showed significantly more contrast than the absolute pitch group, $F(1,5)=50.53, p<.0001$, but neither the Trials effect nor the Trials by Groups Interaction were significant.

A t test revealed that the average degree of contrast shown by the control subjects was significantly different from zero, $t(5)=23.62, p<.001$. There does appear to be some contrast effect for the absolute pitch group as well. The effect, although small in magnitude, was consistent over all six postshift trial blocks for three subjects, and over $5 / 6$ blocks for two others. The remaining subject showed assimilation, rather than contrast, as her standard score had a value of +.04 . For the absolute pitch group, the contrast effect was statistically signifi-

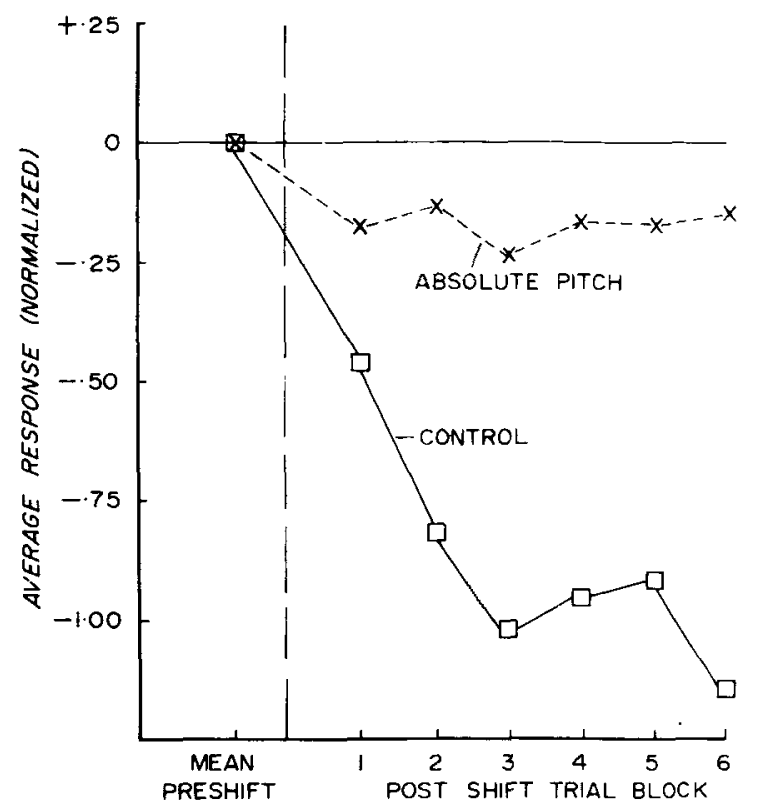

Figure 6. Mean magnitude estimates of single tones varying in frequency by absolute pitch and control subjects following a shift in the stimulus range (standard scores).

cant, $\mathrm{t}(5)=3.33, \mathrm{p}<.05$. This finding probably reflects the fact that absolute pitch is much less common among musicians than relative pitch, and it is difficult to find individuals with well-anchored note categories. We do not find this surprising, since absolute pitch has little functional value for the enjoyment or performance of music.

We also examined the correlation between pitchnaming ability, as assessed in the pretest, with the degree of contrast shown by each of 27 individuals tested in this study, and found it to be statistically significant, $r=.62, p<.01$. While there are large individual differences in the ability to identify tone frequency on an absolute, context-free basis, it seems that musicians at the upper end of the pitch-naming continuum are able to perform at a level approaching that of speech.

\section{DISCUSSION}

In this series of four experiments, we examined the ability of persons with varying degrees of musical training to identify pitch on an absolute basis. We found that for nonmusicians, the ability to categorize notes or intervals was severely limited, a result that corresponds with those of earlier experiments (e.g., Pollack, 1952; W. Siegel, 1972). Persons lacking musical training were unable to identify pitch variations reliably, and their performance was greatly dependent upon the stimulus context. Thus, we found that, for them, shifts in the stimulus range 
gave rise to strong contrast effects in the judgment of both single tones and intervals.

On the other hand, musicians with good relative pitch were able to assign interval names to the frequency ratio continuum accurately, reliably, and with little overlap between adjacent categories. For the best subjects, naming distributions generated on two tests separated by at least 1 month agreed very well with one another. Moreover, shifting the stimulus range had little or no effect on the judgments of the best of these subjects. Similarly, possessors of absolute pitch were able to categorize variations in tone frequency on an absolute basis with a high degree of reliability, and their responses were relatively free from context effects. In general, the performance of our musicians was akin to that obtained in a number of studies examining the identification of speech stimuli (e.g., Liberman, 1970; Sawusch \& Pisoni, 1974; Sawusch et al., 1974; Pisoni, Note 1).

Absolute, context-free identification is one of several phenomena that have led a number of writers to argue that the perceptual processing of speech is "special." In addition, it has been demonstrated that, while nonspeech acoustic dimensions are perceived continuously, those relevant for the perception of speech are perceived categorically (Liberman, Cooper, Shankweiler, \& Studdert-Kennedy, 1967). That is, subjects typically fail to detect fine acoustic gradations among members of the same phoneme class; instead, they detect only those differences that are important for linguistic meaning. The categorical perception of speech is associated with left-hemisphere dominance, while nonspeech acoustic stimuli, such as melodies and environmental noises, are thought to be processed primarily by the right hemisphere (Kimura, 1961, 1964; StuddertKennedy \& Shankweiler, 1970). Moreover, it has been suggested that for speech signals, categorical perception is mediated by specialized neural feature detectors that are tuned to pick up phonemic information and to reject fine-grained acoustic information that is irrelevant to meaning (Eimas \& Corbit, 1973). These feature detectors are thought to comprise a special speech processor which is operative as early as 1 month of age (Eimas et al., 1971) and which is thought to be part of man's species-specific capacity for language. According to this view, the interesting phenomena associated with the perception of speech result from the operation of this innate speech processor.

An alternative hypothesis is that at least some of the apparent uniqueness of speech stems from the large amount of experience that most of us have had in listening to and producing language. This conclusion is supported by the present experiments, which demonstrate absolute, context-free judgment of notes and intervals by musicians with absolute and relative pitch. Moreover, several recent studies have demonstrated that categorical perception is not unique to speech, but also is characteristic of the processing of notes, intervals, and chords by musicians (Burns \& Ward, 1974, 1975; Harris \& J. Siegel, 1975; Locke \& Kellar, 1973; W. Siegel \& Sopo, 1975). Finally, Bever and Chiarello (1974) have found that, in a dichotic listening experiment, nonmusicians showed the typical right-hemisphere dominance in the processing of music, but musicians showed left-hemisphere dominance, a phenomenon more usually associated with speech.

In this paper, we have assumed that our musician's note and interval categories were acquired through their musical training. Certainly, there are a number of writers who would take exception with this view, and who would argue that the Western musical scale has a natural basis, on either mathematical or acoustic grounds (cf. Meyer, 1956). At the same time, the nonmusicians in the present experiments were unable to identify notes and intervals accurately or reliably on an absolute basis. Furthermore, there is considerable cross-cultural variation in both scale forms and absolute tuning (e.g., Hood, 1971), and even the current standard pitch for Western music $(\mathrm{A}=440 \mathrm{~Hz})$ has been adopted only since 1939 (cf. Jeans, 1968, pp. 23-24). In Javanese music, there is no standard "concert pitch"; the instruments of a gamelan orchestra are tuned to each other on a relative basis. Susilo, an Indonesian ethnomusicologist, has indicated to us (Susilo, Note 2) that absolute pitch does not exist in Java and that there is no word for absolute pitch in the language. Thus both absolute and relative pitch appear to depend heavily upon culturally defined learning experiences.

It is interesting that while it is common among psychologists to contrast speech and nonspeech auditory processing, a number of musicians have drawn an analogy between speech and music (Nettl, 1958; Seeger, 1960). Bright (1963) summarizes the situation as follows: "Every culture in the world presumably has language, and every culture also has music. These two departments of human culture have some important similarities and points of contact; perhaps the most obvious of these lies in the fact that language and music are the two most important ways that man uses sound"' (p. 26). The research reported here has been in part motivated by this point of view. Among musicians, at least, both speech and music comprise important and frequent acoustic events. It is not surprising therefore, that they should be processed perceptually in a similar manner.

\section{REFERENCE NOTES}

1. Pisoni, D. B. On the nature of the categorical perception of speech sounds. Status Report on Speech Research SR-27. Haskins Laboratories. New Haven, 1971.

2. Susilo. Personal communication, August $19^{75}$. 


\section{REFERENCES}

Abramson, A. S., \& Lisker, L. Discriminability along the voicing continuum: Cross-language tests. In Proceedings of the 6th International Congress of Phonetic Sciences (Prague, 1967). Prague: Academia, 1970. Pp. 569-573.

BACHEM, A. Various types of absolute pitch. Journal of the Acoustical Society of A merica, 1937, 9, 146-151.

Bever, T., \& ChIARIEllo, R. J. Cerebral dominance in musicians and nonmusicians. Science, 1974, 185, 537-539.

Brady, P. T. Fixed-scale mechanism of absolute pitch. Journal of the Acoustical Society of A merica, 1970, 48, 883-887.

BRIGHT, W. Language and music: Areas for cooperation. Ethnomusicology, 1963, 7, 26-32.

BURns, E. M., \& WARD, W. D. Categorical perception of musical intervals. Journal of the Acoustical Society of America, 1974, $55,456$.

BuRNS, E. M., \& WARD, W. D. Further studies in musical interval perception. Journal of the Acoustical Society of America, 1975, 58, S132.

CudDy, L. Practice effects in absolute judgments of pitch. Journal of the Acoustical Society of America, 1968, 43, 1069-1076.

DiLollo, V., \& Kirkham, R. Judgmental contrast effects in relation to range of stimulus values. Journal of Experimental Psychology, 1969, 81, 421-427.

Durlach, N. I., \& Braida, L. D. Intensity perception. I. Preliminary theory of intensity resolution. Journal of the Acoustical Society of America, 1969, 46, 372-383.

Ermas, P. D. Auditory and phonetic encoding of the cues for speech: Discrimination of the $(r-1)$ distinction by young infants. Perception \& Psychophysics, 1975, 18, 341-347.

Eimas, P. D., \& CoRBIT, J. D. Selective adaptation of linguistic feature detectors. Cognitive Psychology, 1973, 4, 99-109.

Emas, P. D., Siqueland, E. R., Jusczyk, P., \& Vigorito, J. Speech perception in infants. Science, 1971, 171, 303-306.

Harris, G., \& Siegel, J. A. Categorical perception and absolute pitch. Journal of the Acoustical Society of America, 1975, 57, S11.

HELMHOLtz, H. On the sensations of tone. New York: Dover, 1954.

Helson, H. Adaptation-level theory. New York: Harper \& Row, 1964.

Hood, M. The ethnomusicologist. New York: McGraw-Hill, 1971.

JeANs, J. Science and music. New York: Dover, 1968.

KImURA, D. Cerebral dominance and the perception of verbal stimuli. Canadian Joumal of Psychology, 1961, 15, 166-171.

KIMURA, D. Left-right differences in the perception of melodies. Quarterly Joumal of Experimental Psychology, 1964, 16, 355-358.

LIB ERMAN, A. M. Some characteristics of perception in the speech mode. In D. A. Hamburg (Ed.), Perception and its disorders: Proceedings of A.R.N.M.D. Baltimore: Williams \& Wilkins, 1970.

Liberman, A. M., Cooper, F. S., Shankweiler, D. S., \& Studdert-Kennedy, M. Perception of the speech code. Psychological Review, 1967, 74, 431-461.

Lisker, L., \& Abramson, A. S. A cross-language study of voicing in initial stops: Acoustical measurements. Word, 1964, 20, 384-422.

Locke, S., \& Kellar, L. Categorical perception in a nonlinguistic mode. Cortex, 1973, 9, 355-368.

MEYER, L. B. Emotion and meaning in music. Chicago: University of Chicago Press, 1956.

MEYER, M. Is the memory of absolute pitch capable of development by training? Psychological Review, 1899, 6, 514-516.

MilleR, G. A. The magical number seven plus or minus two: Some limits on our capacity for processing information. Psychological Review, 1956, 63, 81-96.

Miyawaki, K., Strange, W., Verbrugge, R., Liberman, A. M., Jenkins, J. J., \& Fujtmura, O. An effect of linguistic experience: The discrimination of $(r)$ and (1) by native speakers of Japanese and English. Perception \& Psychophysics, 1975, 18, 331-340.

Mul, H. K. The acquisition of absolute pitch. American Journal of Psychology, 1925, 36, 469-493.

NETTL, B. Some lingusitic approaches to musical analysis. Journal of the International Folk Music Council, 1958, 10, 37.41.

NEU, D. M. A critical review of the literature on "Absolute Pitch." Psychological Bulletin, 1947, 44, 249-266.

OAKEs, W. F. An experimental study of pitch naming and pitch discrimination reactions. Journal of Genetic Psychology, 1955, 86, 237-259.

Parducci, A. Category judgment: A range-frequency model. Psychological Review, 1965, 72, 407-418.

Petran, L. A. Experimental study of pitch recognition. Psychological Monographs, 1932, 42(Whole No. 6).

Pollack, 1. The information of auditory displays. Journal of the Acoustical Society of A merica, 1952, 24, 745-749.

Pollack, I. The information of elementary auditory displays, II. Journal of the Acoustical Society of America, 1953, 25, 765-769.

Revesz, G. Zur "Grundlegung der Tonpsychologie." Leipzig: Weit, 1913.

Rike R, B. L. The ability to judge pitch. Joumal of Experimental Psychology, 1946, 36, 331-346.

Ross, J., \& DiLollo, V. Judgment and response in magnitude estimation. Psychological Review, 1971, 78, 515-527.

Sawusch, J. R., \& Pisoni, D. B. Category boundaries for speech and non-speech sounds. Journal of the Acoustical Society of America, 1974, 55, 436.

Sawusch, J. R., Pisoni, D. B., \& Curting, J. E. Category boundaries for linguistic and non-linguistic dimensions of the same stimuli. Journal of the Acoustical Society of America, 1974, 55, 555 .

SEEGER, C. On the moods of a music-logic. Journal of the American Musicological Society, 1960, 13, 224-261.

Siegel, J. A., \& Siegel, W. Absolute judgment and pairedassociate learning: Kissing cousins or identical twins? Psychological Review, 1972, 79, 300-316.

SIEGEL, W. Memory effects in the method of absolute judgment. Journal of Experimental Psychology, 1972, 94, 121-131.

SIEGEL, W., \& Sopo, R. Tonal intervals are perceived categorically by musicians with relative pitch. Joumal of the Acoustical Society of America, 1975, 57, S11.

Studdert-Kennedy, M., Liberman, A. M., Harris, K., \& COOPER, F. S. The motor theory of speech perception: A reply to Lane's critical review. Psychological Review, 1970, 77, 234-249.

Studdert-Kennedy, M., \& Shankweiler, D. Hemispheric specialization for speech perception. Journal of the Acoustical Society of America, 1970, 48, 579-594.

STUMPF, C. Tonpsychologie. Leipzig: S. Hirzal, 1883.

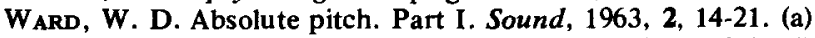

WARD, W. D. Absolute pitch. Part II. Sound, 1963, 2, 33-41. (b)

WARD, L. M., \& LoCKHEAD, G. R. Sequential effects and memory in category judgments. Joumal of Experimental Psychology, $1970,84,27-34$.

Weintraub, D. J. Rectangle discriminability: Perceptual relativity and the law of pragnanz. Journal of Experimental Psychology, $1971,88,1-11$.

(Received for publication March 17, 1976; revision accepted October $15,1976$. 